\title{
Pengaruh EWOM, Travel Motivation dan Destination Attractiveness terhadap Visit Intention di Kota Batam
}

\author{
Ratih Anggraini \\ Universitas Internasional Batam, Batam, Indonesia \\ $\underline{\text { ratih@uib.ac.id }}$

\section{Noviyanti Lupita} \\ Universitas Internasional Batam, Batam, Indonesia \\ noviyanti.lupita@yahoo.com
}

\begin{abstract}
Abstrak Niat berkunjung Kembali pada suatu objek wisata adalah salah satu tolak ukur keberhasilan sebuah destinasi wisata dalam memberikan kepuasan kepada pelanggan. EWOM, motivasi, dan daya tarik destinasi memiliki peran penting dalam keputusan calon wisatawan dalam mengunjungi suatu destinasi wisata. Salah satu destinasi wisata pada penelitian ini adalah Kota Batam. Penelitianini menggunakan metode kuantitatif dikarenakan melakukan uji hipotesis dan mendeskripsikan hubungan antar variabel. Tujuan dari penelitian ini yaitu untuk memperjelas dan mengetahui apakah EWOM, motivasi, daya tarik destinasi berpengaruh secara signifikan bagi calon wisatawan dalam membuat keputusan untuk berkunjung ke suatu destinasi wisata di Kota Batam. Observasi dilaksanakan dengan cara menyebarkan kuisioner berupa google form yang disebar melalui media sosial seperti line dan whatsapp untuk dapat menjangkau calon wisatawan luar kota. Narasumber yang terkumpul sebanyak 272 responden diantaranya terdapat 173 wanita dan 99 pria. Teknik yang dipakai dalam penelitian ini adalah snowball sampling yang artinya narasumber satu mereferensikan kepada yang lain dan seterusnya sehingga akhirnya responden menjadi besar. Penulis melakukan uji data menggunakan IBM SPSS Statistic setelah responden sudah terkumpul. Pada hasil penelitian, pada uji $\mathrm{T}$ menunjukan bahwa motivasi tidak memiliki pengaruh secara signifikan terhadap niat untuk berkunjung. Sedangkan EWOM dan daya tarik destinasi berpengaruh cukup signifikan terhadap niat untuk berkunjung dengan nilai sig $\leq 0.05$ yaitu 0.00 .
\end{abstract}

Kata Kunci observasi, EWOM, motivasi, daya tarik destinasi, niat untuk berkunjung

\section{PENDAHULUAN}

Industri Pariwisata dalam beberapa tahun terakhir menjadi salah satu sector Industri yang menjadi sorotan karena berdampak pada ekonomi global. Sektor pariwisata berlombalomba untuk memberikan kualitas terbaik yang mereka miliki agar dapat bersaing dengan Pariwisata Dunia. Berdasarkan data dari The World Travel \& Tourism Council (WTTC), pariwisata di Indonesia berada pada peringkat 9 per tahun 2018, pemerintah masih terus melakukan upaya pembangunan di bidang pariwisata pada setiap wilayah Indonesia. Salah satu kota yang menjadi daya tarik pada bidang pariwisata adalah kota Batam. Per 
November 2017 lalu, Kota Batam pun telah disepakati untuk dijadikan Kota wisata. (https://www.batamnews.co.id/). Dinas kebudayaan dan Pariwisata Kota Batam juga menyatakan bahwa kunjungan wisatawan sudah tembus satu juta orang di bulan ke tujuh pada tahun 2019 dan terus meningkat sepuluh persen dari bulan sebelumnya. (https://sumatra.bisnis.com/). Meningkatnya ekonomi di bidang pariwisata, tidak terlepas dari peran teknologi zaman ini. Maraknya penggunaan media dapat membawa dampak dengan munculnya Electonic Word of Mouth (EWOM) yang membuat wisatawan mendapatkan gambaran tentang destinasi yang akan di kunjungi di masa yang akan datang. Peran dari EWOM sendiri khususnya pada bidang pariwisata memiliki perkembangan sangat pesat sehingga meningkatkan jumlah wisatawan dalam penggunaan internet dengan tujuan melakukan pencarian informasi. Maraknya penggunaan media dapat membawa dampak dengan munculnya Electonic Word of Mouth (EWOM) yang membuat wisatawan mendapatkan gambaran tentang destinasi yang akan di kunjungi di masa yang akan datang. Motivasi wisatawan juga menjadi faktor utama yang perlu di miliki oleh calon wisatawan dalam mengambil keputusan untuk berkunjung. Setiap calon wisatawan pasti memiliki motivasi untuk berkunjung ke destinasi wisata untuk memberikan kepuasan kepada diri sendiri. Selain membutuhkan suasana baru untuk mengurangi kejenuhan, motivasi untuk melakukan perjalanan wisata juga didasari oleh rasa bosan terhadap lingkungan yang monoton, seperti perkantoran dan aktivitas yang sama setiap harinya. Tingkat kunjungan wisatawan, relatifnya dipengaruhi oleh daya tarik wisata. Daya tarik wisata dapat dikatakan adalah motivasi utama dalam melakukan perjalanan (Witt \& Mountinho, 1994). Selain itu, dapat dikatakan pula sebagai suatu hal yang memiliki daya tarik untuk dinikmati dan dilihat yang memadai dijual ke pasar wisata. Berdasarkan latar belakang yang sudah disampaikan diatas, penulis tertarik untuk melakukan penelitian dengan mengambil judul "Pengaruh EWOM, Motivation dan Destination Atrractiveness terhadap Visit Intention di Kota Batam".

\section{LANDASAN TEORI \\ 1. Visit Intention}

Niat adalah sesuatu yang melibatkan perilaku karena mendasari seseorang untuk melakukannya (Oliver, 1997). Keinginan atau niat adalah kesenangan atau kehendak dari seseorang dalam melaksanakan suatu hal terkait dengan perilaku (Kamisa, 1997). Albarq (Albarq, 2014) menyatakan bahwa keinginan melaksanakan perjalanan adalah tindakan yang diambil saat hendak melakukan darmawisata ke tempat tertentu yang ingin dituju. Intention dalam suatu darmawisata tidak bersifat absolut, hal ini disebabkan ada nya kesempatan yang dialami oleh pengunjung dapat ber ubah tiba-tiba dan menghasilkan tindakan serta resolusi akhir (Jang et al., 2009). Niat untuk mengunjungi suatu destinasi didefinisikan sebagai keinginan untuk mengunjungi. Keputusan untuk berkunjung tersebut di intrepertasikan sebagai perhitungan yang rasional terhadap biaya dan manfaat dari kunjungan yang berasal dari berbagai informasi termasuk EWOM atau bisa juga travel blog. EWOM mempunyai pengaruh 30 kali lebih cepat kepada konsumen dibanding dengan penyebaran informasi secara tradisional (Abubakar \& Ilkan, 2016).

\section{Electronic Word Of Mouth (EWOM)}

E-WOM adalah salah satu jenis pesan yang berasal dari organisasi dan informasi yang dihasilkan biasanya diluar kendali perusahaan. Setiap pengalaman informal terhadap pembelian dan informasi terkait konsumsi di antara para pelanggan di pertimbangkan sebagai EWOM, terlepas dari konten informasi dan karena nya EWOM bisa menjadi 
positif maupun negatif. Contohnya seperti konsumen yang puas dan loyal terhadap suatu produk, termasuk contoh pengaruh EWOM yang positif dimana dapat membantu perusahaan dalam promosi dan menarik konsumen lain. (Krishnapillai \& Ying, 2017).

E-WOM dianggap sebagai sumber informasi penting yang dapat mempengaruhi niat dan tujuan perjalanan dari wisatawan. Penelitian dari Chevlier pada tahun 2006 juga menunjukan bahwa review online memiliki dampak yang signfikan terhadap penjualan (Fakharyan, 2012).

\section{Motivasi}

Motivasi ialah keadaan psikologis individu yang muncul dikarenakan kebutuhan untuk melakukan suatu tindakan. Motivasi adalah kecenderungan yang muncul karena kebutuhan mendorong suatu individu untuk melakukan berbagai jenis tidakan yang harus dipenuhi. Dalam pariwisata, motivasi membutuhkan arahan dan integrasi seseorang yang berperilaku dan beraktivitas. Dalam berkunjung dan melakukan perjalanan, motivasi harus di ekplorasi lebih lanjut untuk melihat pandangan, situasi, interaksi dan proses yang spesifik dalam menciptakan kebutuhan, dan kebutuhan ini mendorong seseorang untuk melakukan suatu tindakan (Khan et al., 2018).

\section{Destination Attractiveness}

Daya tarik destinasi memiliki dua hal dasar, yaitu permintaan dan penawaran. Permintaan berfokus pada wisatawan sedangkan penawaran berfokus pada tujuan wisata. Permintaan dan penawaran melibatkan empat aspek utama yaitu atraksi, kemudahan, aksesibilitas dan layanan tambahan. Selain permintaan dan penawaran, dayat Tarik destinasi juga memiliki atribut dasar seperti primer, sekunder dan tersier. Primer adalah hal mendasar yang utama seperti lokasi, wilayah yang melibatkan budaya yang ada. Sekunder adalah fakor apa saja yang mendukung area geografis seperti akomodasi dan makanan. Sedangkan tersier adalah kegiatan yang berorientasi pada market untuk meingkatkan data tariknya (Yacob et al., 2019).

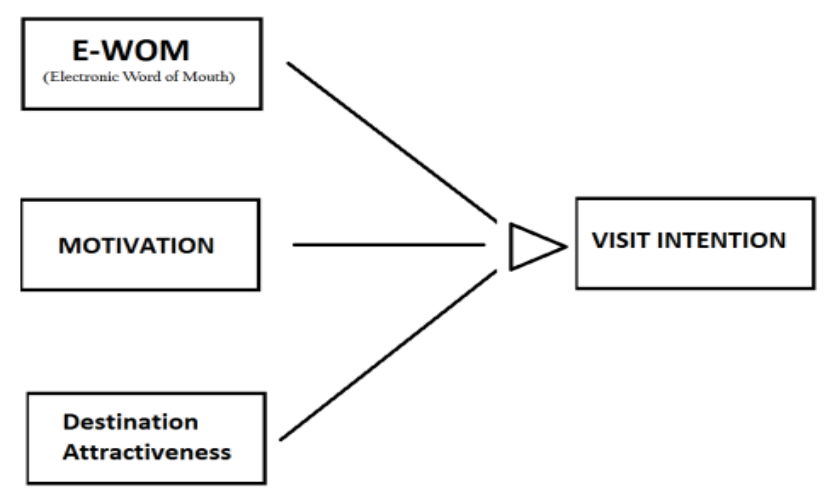

Gambar 1. Model Penelitian

Sumber: Data diolah, 2020

Berlandaskan penelitian dengan model tertera diatas, maka penulis merumuskan hipotesis sebagai berikut:

$\mathrm{H}_{1}$ : Terdapat pengaruh antara EWOM terhadap minat wisatawan untuk berkunjung

$\mathrm{H}_{2}$ : Terdapat pengaruh antara motivasi terhadap minat wisatawan untuk berkunjung 
$\mathrm{H}_{3}$ : Terdapat pengaruh antara destination attractiveness terhadap minat wisatawan untuk berkunjung

\section{METODOLOGI PENELITIAN}

Penggunaan metode dalam observasi ini ialah metode kuantitatif, penelitian dalam hal ini memiliki sifat menguji berbagai hipotesa yang mendeskripsikan fenomena berupa hubungan diantara variable. Penelitian kuantitatif membuat sebuah kesimpulan tentang populasi. Penelitian ini biasanya dikelola menggunakan data empiris (Robinson, 2015). Metode ini memaksimalisasi objektivitas dilaksanakan menggunakan angka dan pengolahan statistic (Sukmadinanta, 2009). Metode kuantitatif juga merupakan cara yang digunakan dalam menjawab masalah penelitian yang berhubungan dengan data berupa angka dan program statistic (Wahidmurni, 2017).

Populasi yang ditentukan dalam observasi ini ialah penduduk Indonesia daerah lain yang mengunjungi Kepulauan Riau dengan jumlah populasi yang di dapatkan dari BPS pada tahun 2018 sebanyak 4.227 .770 orang. Penelitian ini memakai kuisioner yang disebarkan berjumlah 272 data. Ukuran sampel yang dipakai dalam penelitian adalah Hair et al (Joseph et al., 2010). Rumus dari sampel yang berupa Hair et al terlampir sebagai berikut:

\section{Sampel $=$ total indikator $\mathbf{x} 10$}

\section{Gambar 2. Rumus Perhitungan Sampel Sumber: (Joseph et al., 2010)}

Snowball sampling digunakan menjadi metode pemilihan sampel dalam penelitian. Sampling ini digunakan dikarenakan peneliti tidak mengetahui calon responden, sehingga key informan (orang yang memiliki dan mengetahui berbagai informasi dasar yang dibutuhkan dalam penelitian) dapat membantu dalam menentukan jumlah responden yang dikehendaki sehingga dapat terpenuhi.

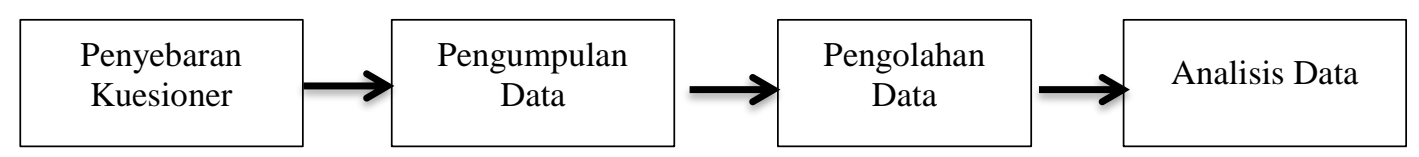

\section{Gambar 3. Tahapan Penelitian}

Sumber: Data diolah, 2020

Teknik pengumpulan data yang digunakan dalam penelitian ini yaitu melalui penyebaran kuesioner dengan google form yang disebarkan melalui sosial media, seperti line dan whatsapp. Responden dari penelitian ini yaitu penduduk Indonesia daerah lain yang mengunjungi Kepulauan Riau. Proses penyeberan kuesioner dilakukan selama 2 bulan, yaitu mulai dari bulan Oktober-Desember 2019. Data yang telah dikumpulkan sebanyak 272 responden.

Metode dalam menganalisis pada penelitian ini menggunakan software IBM SPSS Statistik dengan penerapan analisis deskriptif yang digunakan untuk memberikan gambaran yang teratur, ringkas dan jelas terhadap suatu keadaan sehingga dapat disimpulkan sebagai pengertian atau makna tertentu (Amirotun, 2016). Selanjutnya dilakukan uji kualitas data observasi yang menjadi solusi dari permasalahan dalam observasi yang dilakukan berlandaskan hasil proses uji data seperti penyeleksi kemudian 
pengumpulan dan analisis data di sebut juga dengan uji kualitas data (Indriantoro \& Supomo, 2012). Uji kualitas data dikelompokkan menjadi 2 bagian yaitu validitas dan reliabilitas. Pengujian selanjutnya yaitu uji asumsi klasik yang terdiri dari uji outlier, uji normalitas, uji multikolinieritas, dan uji heteroskedastisitas. Setelahnya dilakukan uji hipotesis yang terdiri dari Uji F dan Uji T.

\section{HASIL PENELITIAN}

\section{DESKRIPSI DEMOGRAFI RESPONDEN}

Proses pengumpulan data dilakukan melakukan dengan google form yang disebarkan melalui sosial media, seperti line dan whatsapp. Responden dari penelitian ini yaitu penduduk Indonesia daerah lain yang mengunjungi Kepulauan Riau. Proses penyeberan kuesioner dilakukan selama 2 bulan, yaitu mulai dari bulan Oktober-Desember 2019. Data yang telah dikumpulkan sebanyak 272 responden.

\section{Tabel 1}

Karakteristik Responden

\begin{tabular}{|c|c|c|}
\hline Ukuran Sampel & $\begin{array}{c}\text { Frekue } \\
\text { nsi }\end{array}$ & Presentase \\
\hline \multicolumn{3}{|l|}{ Jenis Kelamin } \\
\hline Laki-Laki & 99 & $36.4 \%$ \\
\hline Perempuan & 173 & $63.6 \%$ \\
\hline \multicolumn{3}{|l|}{ Usia } \\
\hline$<20$ tahun & 29 & $10.7 \%$ \\
\hline 21-30 tahun & 155 & $57.0 \%$ \\
\hline 31-40 tahun & 67 & $26.4 \%$ \\
\hline$>40$ tahun & 21 & $7.7 \%$ \\
\hline \multicolumn{3}{|l|}{ Pendidikan Terakhir } \\
\hline SMP Sederajat & 2 & $0.7 \%$ \\
\hline SMA Sederajat & 171 & $62.9 \%$ \\
\hline Sarjana & 95 & $34.9 \%$ \\
\hline Magister & 5 & $1.5 \%$ \\
\hline \multicolumn{3}{|l|}{ Status Pekerjaan } \\
\hline Karyawan & 162 & $59.6 \%$ \\
\hline Mahasiswa/i & 66 & $24.3 \%$ \\
\hline Ibu Rumah Tangga & 40 & $14.7 \%$ \\
\hline Hamba Tuhan & 2 & $0.7 \%$ \\
\hline Profesional & 2 & $0.7 \%$ \\
\hline \multicolumn{3}{|l|}{ Tingkat Pendapatan } \\
\hline$<3.000 .000$ & 16 & $5.9 \%$ \\
\hline $3.000 .000-5.000 .000$ & 110 & $40.4 \%$ \\
\hline $5.000 .000-7.000 .000$ & 61 & $22.4 \%$ \\
\hline$>7.000 .000$ & 85 & $31.3 \%$ \\
\hline \multicolumn{3}{|l|}{ Pengetahuan tentang Batam } \\
\hline $\mathrm{Ya}$ & 270 & $99.3 \%$ \\
\hline Tidak & 2 & $0.7 \%$ \\
\hline \multicolumn{3}{|l|}{ Sumber Informasi } \\
\hline Belum Pernah & 2 & $0.7 \%$ \\
\hline $\begin{array}{l}\text { Sosial Media (Instagram, } \\
\text { Facebook, Twitter) }\end{array}$ & 170 & $62.5 \%$ \\
\hline
\end{tabular}




\begin{tabular}{ccc}
\hline Ukuran Sampel & $\begin{array}{c}\text { Frekue } \\
\text { nsi }\end{array}$ & Presentase \\
\hline Website & 48 & $17.6 \%$ \\
Media Cetak & 16 & $5.9 \%$ \\
Saudara & 17 & $6.3 \%$ \\
Teman & 15 & $5.5 \%$ \\
Keluarga & 4 & $1.5 \%$ \\
\hline
\end{tabular}

Sumber : Hasil olah data primer (2020)

Kuisioner yang berhasil dikumpulkan berjumlah 272 responden. Dengan persentase $36.4 \%$ yaitu 99 orang laki-laki dan $63.6 \%$ yaitu 173 orang perempuan. Responden juga dikelompokkan menjadi berbagai usia. $\leq 20$ tahun terdapat 29 responden atau $10.70 \%, \geq$ 21 - 30 tahun terdapat 155 orang responden atau 57\%, $\geq 31$ - 40 tahun terdapat 67 responden atau $24.60 \%$, yang terakhir $>40$ tahun terdapat 21 responden atau $7.70 \%$. Responden berdasarkan pendidikan terakhir berupa SMP sederajat terdapat 2 responden atau $0.70 \%$, SMA sederajat terdapat 171 orang atau 62.90\% . Untuk Sarjana terdapat 95 orang atau $34.90 \%$, sedangkan yang Magister terdapat 5 orang atau $1.50 \%$. Responden juga terbagi berdasarkan status pekerjaan. Terdapat 162 karyawan atau $59.60 \%$. Mahasiswa/I terdapat 66 responden atau $24.30 \%$. Ibu rumah tangga terdapat 40 orang atau $14.70 \%$. Hamba Tuhan terdapat 2 orang atau $0.70 \%$, sedangkan professional terdapat 2 orang atau $0.70 \%$.Terdapat pula pembagian responden berdasarkan pengetahuan tentang kota Batam. Terdapat 270 orang atau $99.30 \%$ responden yang mengenal kota Batam. Dan 2 orang atau $0.70 \%$ yang tidak mengenal kota Batam. Selain itu, responden di kelompokkan berdasarkan informasi yang didapat. Yang belum pernah mendengar tentang kota Batam terdapat 2 orang atau $0.70 \%$. Yang mengetahui melalui social media terdapat 170 orang atau $62.50 \%$. Yang mengetahui melalui Website terdapat 48 responden atau $17.60 \%$, melalui media cetak terdapat 16 orang atau 5.90\%. Melalui saudara terdapat 17 orang atau $6.30 \%$, melalui teman terdapat 15 orang atau 5.5\%. Yang terakhir melalui keluarga terdapat 4 orang atau $1.50 \%$.

\section{HASIL UJI STATISTIK DESKRIPTIF}

\begin{tabular}{|c|c|}
\hline \multicolumn{2}{|c|}{$\begin{array}{c}\text { Tabel } 2 \\
\text { Hasil Uji Statistik Deskriptif }\end{array}$} \\
\hline Variabel & Mean \\
\hline EWOM & 4,60 \\
\hline Motivasi Berkunjung & 4,60 \\
\hline Daya Tarik Wisata & 4,51 \\
\hline Intention to Visit & 4,42 \\
\hline
\end{tabular}

Pengujian dilakukan menggunakan IBM SPSS Statistik dengan menunjukan hasil bahwa responden berpendapat bahwa EWOM dinilai cukup baik (4.60), motivasi untuk berkunjung juga dinilai baik dari hasil tersebut $(4,60)$. Kemudian daya tarik wisata memilki nilai yang cukup baik $(4,51)$ juga keinginan untuk berkunjung memiliki nilai yang baik $(4,42)$. 


\section{HASIL UJI KUALITAS DATA} Uji Outlier

\section{Tabel 3}

Statistik uji outlier

\begin{tabular}{ccc}
\hline Subject & Variable Outlier & Nilai Outlier \\
\hline Narasumber 61 & ZMotivasi Berkunjung & $-3,65$ \\
Narasumber 128 & ZEWOM & $-3,34$ \\
\hline
\end{tabular}

Sumber: Hasil olah data primer (2020)

Jika pada data terdapat nilai $z$-score $\leq-3,0$ atau $\geq$ dari 3,0 maka data tersebut dapat dikatakan outlier dengan kata lain melenceng dari rata-rata. Tabel diatas menunjukan bahwa terdapat 2 narasumber outlier, artinya kedua responden tersebut akan dikeluarkan untuk pengujian selanjutnya.

\section{Uji Validitas}

Apabila nilai yang dihasilkan lebih kecil dari 0.3 dalam sebuah penelitian, maka pertanyaan tersebut dinyatakan tidak valid dan pertanyaan penelitian tersebut harus dikeluarkan untuk uji selanjutnya (Santoso, 2001). Hasil dari pengujian validitas penelitian terlihat pada tabel berikut:

Tabel 4 Uji Validitas

\begin{tabular}{lccc}
\hline Variabel & $\begin{array}{c}\text { Butir } \\
\text { Pertanyaan }\end{array}$ & $\begin{array}{c}\text { Loading } \\
\text { Factor }\end{array}$ & Kesimpulan \\
\hline EWOM & $1 \mathrm{Q}$ & 0.724 & Valid \\
& $2 \mathrm{Q}$ & 0.850 & Valid \\
& 3Q & 0.798 & Valid \\
Motivation & $4 \mathrm{Q}$ & 0.799 & Valid \\
& $1 \mathrm{Q}$ & 0.577 & Valid \\
& $2 \mathrm{Q}$ & 0.600 & Valid \\
& $3 \mathrm{Q}$ & 0.712 & Valid \\
& $4 \mathrm{Q}$ & 0.696 & Valid \\
& $5 \mathrm{Q}$ & 0.622 & Valid \\
& $6 \mathrm{Q}$ & 0.810 & Valid \\
Destination & $7 \mathrm{Q}$ & 0.533 & Valid \\
& $8 \mathrm{Q}$ & 0.544 & Valid \\
& $1 \mathrm{Q}$ & 0.811 & Valid \\
& $2 \mathrm{Q}$ & 0.838 & Valid \\
& $3 \mathrm{Q}$ & 0.728 & Valid \\
& $4 \mathrm{Q}$ & 0.853 & Valid \\
& $5 \mathrm{Q}$ & 0.792 & Valid \\
& $6 \mathrm{Q}$ & 0.883 & Valid \\
& $7 \mathrm{Q}$ & 0.845 & Valid \\
& $8 \mathrm{Q}$ & 0.868 & Valid
\end{tabular}




\begin{tabular}{lccc}
\hline \multicolumn{1}{c}{ Variabel } & $\begin{array}{c}\text { Butir } \\
\text { Pertanyaan }\end{array}$ & $\begin{array}{c}\text { Loading } \\
\text { Factor }\end{array}$ & Kesimpulan \\
\hline Visit & $1 \mathrm{Q}$ & 0.792 & Valid \\
Intention & 2Q & 0.843 & Valid \\
& 3Q & 0.889 & Valid
\end{tabular}

Sumber : Hasil olah data primer (2020)

Apabila nilai yang dihasilkan lebih kecil dari 0.3 dalam sebuah penelitian, maka pertanyaan tersebut dapat dikatakan tidak valid dan pertanyaan penelitian tersebut harus dikeluarkan untuk uji selanjutnya (Santoso, 2001). Dari 223 item pertanyaan di atas memiliki nilai yang lebih besar dari 0.3 maka dapat dinyatakan bahwa seluruh item pertanyaan tersebut valid dan dapat digunakan dalam pengujian selanjutnya.

\section{Uji Reliabilitas}

Uji reabilitas dapat dilaksanakan apabila masing-masing pertanyaannya sudah dinyatakan valid. Jika jawaban terhadap pertanyaan memiliki konsistensi, maka variable tersebut dapat dikatakan realibel. Jika nilai Cronbach's alpha $\geq 0.6$, maka variable tersebut terbilang realibel (Sujarweni, 2015).

Tabel 5

Uji Reliabilitas

\begin{tabular}{lcc}
\hline Variabel & $\begin{array}{c}\text { Cronbach's } \\
\text { Alpha }\end{array}$ & Kesimpulan \\
\hline EWOM & 0.797 & Reliabel \\
Motivation & 0.775 & Reliabel \\
Destination Attractiveness & 0.933 & Reliabel \\
Visit Intention & 0.780 & Reliabel \\
\hline
\end{tabular}

Sumber: Hasil olah data primer (2020)

Berdasarkan tabel di atas, semua nilai cronbach's alpha dari variable lebih besar dari 0.6. Jadi dapat disimpulkan jika semua variable nya dapat dikatakan reliabel.

\section{HASIL UJI ASUMSI KLASIK}

Berdasarkan hasil uji normalitas, penyebaran dikatakan tidak normal. Hal ini dikarenakan titik-titik tidak mengikuti garis lurus diagonal. Data yang telah diuji juga menunjukan bahwa penyebaran tercacak dan tidak ada pola terbentuk. Artinya adalah data yang dikelola tidak terjadi heteroskedastisitas.

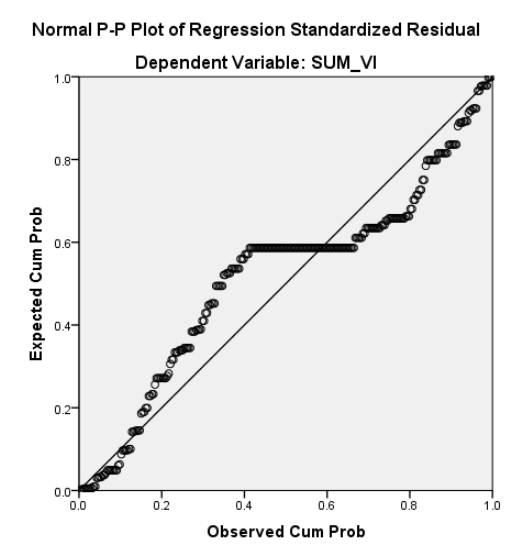

Gambar 4. Hasil Uji Normalitas

Sumber: Hasil olah data primer, 2020 
Sedangkan untuk pengujian Multikolinieritas menunjukkan Saat satu variabel bebas atau lebih, terdapat adanya hubungan yang kuat (korelasi) dalam suatu model regresi berganda, maka variable tersebut dapat disebut dengan multikolinieritas. Jika nilai perhitungan Variance Inflation Factor (VIF) $\leq 10$, maka dikatakan memiliki multikorelitas yang baik. Hasil dari uji penelitian ini, menunjukan hasil penelitian memiliki variable yang tidak menampakkan multikorelitas karena nilai VIF $\leq 10$.

\section{HASIL UJI HIPOTESIS}

Uji f biasa diketahui sebagai uji serentak dengan artian untuk melihat sejauh manakah hubungan dari variable be bas nya terhadap variable terikat. Uji F juga berfungsi sebagai uji yang memperlihatkan model regresi dalam penelitian signifikan atau non signifikan. Tingkat signifikan dalam uji ini adalah $\leq 0.05$.

\section{Tabel 6}

Hasil uji f

\begin{tabular}{|cccc|}
\hline Model & $\boldsymbol{F}$ & Sig. & $\begin{array}{c}\text { Keteranga } \\
\mathbf{n}\end{array}$ \\
\hline Regression & 232.044 & $.000^{\mathrm{b}}$ & Signifikan \\
\hline \multicolumn{4}{l}{ Sumber: Hasil olah data primer (2020) }
\end{tabular}

Tabel di atas menunjukan bahwa nilai sig $\leq$ dari 0.05 yaitu memiliki nilai 0.00 . Maka dapat diartikan sebagai variable bebas berupa EWOM, motivation dan destination attractiveness mempunyai pengaruh yang cukup signifikan terhadap visit intention. Karenanya, model yang penulis pakai dapat digunakan dalam melaksanakan pengujian kinerja. Untuk uji t, apabila nilai sig $\leq 0.05$ maka variable bebas memiliki dampak terhadap variable terikat. Sebaliknya, apabila sig $\geq 0.05$, maka variable bebas nya tidak berdampak terhadap variable terikat.

Tabel 7

Hasil uji t

\begin{tabular}{|lllcc|}
\hline $\begin{array}{l}\text { Variabel } \\
\text { Independen }\end{array}$ & $\begin{array}{l}\text { Variabel } \\
\text { Dependen }\end{array}$ & Coeficient & Sig & Ket \\
\hline EWOM & $\begin{array}{l}\text { Visit } \\
\text { Intention }\end{array}$ & 0.21 & 0,00 & Sig \\
Motivation & $\begin{array}{l}\text { Visit } \\
\text { Intention }\end{array}$ & 0.09 & 0,28 & NonSig \\
$\begin{array}{l}\text { Destination } \\
\text { Attractivenes }\end{array}$ & $\begin{array}{l}\text { Visit } \\
\text { Intention }\end{array}$ & 0.63 & 0,00 & Sig \\
\hline
\end{tabular}

Sumber: Hasil olah data primer (2020)

\section{H1 EWOM berpengaruh terhadap visit intention}

Hasil dari uji t terhadap variable EWOM menampilkan nilai sig 0.00 berarti tidak lebih besar dari 0.05 . Hal ini menjadikan variable EWOM signifikan atau mempengaruhi visit intention.

\section{H2 Motivation berpengaruh terhadap visit intention}

Hasil dari uji t terhadap variable motivation menampilkan nilai 0.28 berarti lebih besar dari 0.05. Dapat dikatakan bahwa variable motivation tidak signifikan maupun mempunyai pengaruh terhadap visit intention.

\section{H3 Destination attractiveness berpengaruh terhadap visit intention}


Nilai dari uji t terhadap variabel daya tarik wisata ialah sebesar 0.00 berarti lebih kecil dari 0.05 . Maka, terbukti bawasanya variable daya tarik wisata signifikan dan memiliki dampak terhadap visit intention.

\section{PEMBAHASAN}

Berdasarkan hasil penelitian di atas, maka dapat diinterpretasikan sebagai berikut:

1. Hasil anallisis untuk variabel EWOM memiliki pengaruh yang positif dan signifikan terhadap visit intention. Hal tersebut menunjukkan bahwa semakin banyak review online yang positif, maka akan semakin meningkatkan keinginan calon wisatawan untuk berkunjung ke Kota Batam. Untuk itu, perlu bagi suatu destinasi wisata agar memperhatikan kepuasan wisatawan agar dapat menciptakan EWOM yang positif.

2. Motivation tidak memiliki pengaruh yang signifikan terhadap visit intention. Hal tersebut menunjukkan bahwa adanya perbedaan dalam kepentingan dan harapan wisatawan dalam melakukan perjalanan wisata tidak menjadikan keinginan mereka untuk berkunjung ke suatu destinasi wisata menurun. Dengan demikian, calon wisatawan dapat menyesuaikan diri dengan motivasi yang mereka miliki dalam mengunjungi suatu destinasi wisata.

3. Destination attractiveness berpengaruh secara signifikan positif terhadap visit intention. Dengan demikian, daya tarik yang dimiliki oleh suatu destinasi wisata menjadi salah satu pertimbangan bagi calon wisatawan untuk mengunjungi destinasi wisata tersebut. Untuk itu, penting bagi suatu destinasi wisata dalam meningkatkan daya tarik wisata serta sarana dan prasarananya agar dapat menarik minat calon wiatawan agar mengunjungi destinasi wisata tersebut.

4. Dari hasil penelitian ini tidak sepenuhnya mendukung hipotesis yang diajukan dalam penelitian ini, yang mana sebagian variabel berpengaruh dan variabel lainnya tidak berpengaruh terhadap visit intention. Namun, hasil penelitian ini sejalan dengan penelitian terdahulu yang menunjukkan bahwa EWOM berpengaruh signifikan terhadap visit intention (Albarq, 2014; Zarrad \& Debabi, 2015) dan destination attractiveness berpengaruh signifikan terhadap visit intention (Yacob et al., 2019).

\section{KESIMPULAN}

Tujuan dari penelitian ini adalah agar pertanyaan penelitian berupa EWOM, motivation dan destination attractiveness memiliki pengaruh terhadap minat berkunjung calon wisatawan atau tidak dapat terjawab. Hasil dari pengujian tersebut ialah EWOM dan destination attractiveness mempunyai pengaruh terhadap visit intention. Sedangkan motivation tidak pempunyai pengaruh terhadap visit intention. EWOM dan destination attractiveness memiliki pengaruh besar terhadap niat untuk berkunjung. Dapat diartikan bahwa EWOM dan destination attractiveness sangat membantu calon wisatawan dalam memutuskan kunjungan wisata. Sedangkan motivation tidak memiliki pengaruh signifikan, artinya masih belum menjadi alasan utama masyarakat dalam memiliki keinginan yang kuat untuk berwisata.

\section{UCAPAN TERIMA KASIH}

Terima kasih kepada Universitas Internasional Batam (UIB), Rekan mahasiswa, dan Keluarga. Karya ilmiah ini saya persembahkan untuk seluruh pembaca khususnya yang bergerak pada bidang Pariwisata. Harapan saya akan banyak karya ilmiah yang lahir untuk meningkatkan kualitas penyedia jasa Pariwisata yang dapat memperkuat Ekonomi Pariwisata. 


\section{DAFTAR PUSTAKA}

Abubakar, A. M., \& Ilkan, M. (2016). Impact of online WOM on destination trust and intention to travel: A medical tourism perspective. Journal of Destination Marketing and Management, 5(3), 192-201. https://doi.org/10.1016/j.jdmm.2015.12.005

Alam, S., Pramanik, K., Hossain, E., \& Azam, S. (2016). The Impacts of Visitors 'Attitude on Visit Intention in the Context of Museum Applying SEM: Offering an Alternative Visit Intention Model. 1(1), 1-14.

Albarq, A. N. (2014). Measuring the Impacts of Online Word-of-Mouth on Tourists' Attitude and Intentions to Visit Jordan: An Empirical Study. International Business Research, 7(1), 14-22. https://doi.org/10.5539/ibr.v7n1p14

DIRSECIU, P. (2017). No 主観的健康感を中心とした在宅高齢者における 健康関 連指標に関する共分散構造分析Title. 1-14.

Fakharyan, M. (2012). The influence of online word of mouth communications on tourists' attitudes toward Islamic destinations and travel intention: Evidence from Iran. African Journal of Business Management, 6(33), 10381-10388. https://doi.org/10.5897/ajbm12.628

Https://sumatra.bisnis.com/). (n.d.). Kunjungan Wisatawan ke Batam Tembus 1 juta. Https://www.batamnews.co.id/. (n.d.). Kota Batam SAH menjadi kota Industri.

Jang, S., Bai, B., Hu, C., \& Wu, C. M. E. (2009). Affect, travel motivation, and travel intention: A senior market. Journal of Hospitality and Tourism Research, 33(1), 51-73. https://doi.org/10.1177/1096348008329666

Joseph, H., William, B., Barry, B., \& Anderson, R. (2010). Examining Your Data. Multivariate Data Analysis, 1-58.

Khan, M. J., Chelliah, S., \& Ahmed, S. (2018). Intention to visit India among potential travellers: Role of travel motivation, perceived travel risks, and travel constraints. Tourism and Hospitality Research, 19(3), 351-367. https://doi.org/10.1177/1467358417751025

Krishnapillai, G., \& Ying, K. S. (2017). The Infl uence of Electronic-Word-of-Mouth on Travel Intention among Foreign Students in Malaysia: Does Gender Really Matter? International Review of Management and Marketing, 7(1), 475-483.

Munadhiroh, M. (2007). Korelasi Mengikuti Pengajian Majlis Dzikir Al Khidmah dengan Ukhuwah Islamiyah Jama'ah di Kec Weleri Kab Kendal. 34-51.

Robinson, K. (2015). World heritage listed sites-does it attract tourists? a study of factors influencing Norwegian tourist's intention to visit Unesco's world heritage listed sites.

Sujarweni Wiratna. (2015). Metodologi Penelitian - Bisnis dan Ekonomi. In Metodologi Penelitian.

Yacob, S., Johannes, J., \& Qomariyah, N. (2019). Does Destination Attractiveness and Destination Image Create Increase of Visiting Intention in Indonesia Rural Tourism? Sriwijaya International Journal of Dynamic Economics and Business, 3(2), 122. https://doi.org/10.29259/sijdeb.v3i2.122-133

Zarrad, H., \& Debabi, M. (2015). Analyzing the Effect of Electronic Word of Mouth on Tourists' attitude toward Destination and Travel Intention. International Research Journal of Social Sciences, 4(4), 53-60. Retrieved from www.isca.in 